\title{
A Relevant Screening of Organic Contaminants Present on Freshwater and Pre-Production Microplastics
}

\author{
Claudia Campanale ${ }^{1, *(\mathbb{D})}$, Georg Dierkes ${ }^{2}$, Carmine Massarelli ${ }^{1}\left(\mathbb{D}\right.$, Giuseppe Bagnuolo $^{1}$ and \\ Vito Felice Uricchio ${ }^{1}$ (D) \\ 1 National Research Council, Water Research Institute (CNR-IRSA), 70125 Bari, Italy; \\ carmine.massarelli@ba.irsa.cnr.it (C.M.); giuseppe.bagnuolo@ba.irsa.cnr.it (G.B.); \\ vito.uricchio@ba.irsa.cnr.it (V.F.U.) \\ 2 German Federal Institute of Hydrology (BfG), 56068 Koblenz, Germany; Dierkes@bafg.de \\ * Correspondence: claudia.campanale@ba.irsa.cnr.it
}

Received: 6 October 2020; Accepted: 4 November 2020; Published: 9 November 2020 updates

\begin{abstract}
Microplastics (MPs) have recently been discovered as considerable pollutants of all environmental matrices. They can contain a blend of chemicals, some of them added during the manufacture of plastic to improve their quality (additives) and others adsorbed from the surrounding environment. In light of this, a detailed study about the identification and quantification of target organic pollutants and qualitative screening of non-target compounds present on MPs was carried out in different types of samples: environmental MPs, collected from an Italian river, and pre-production MPs, taken from the plastic industry. Polychlorobiphenyls (PCBs), organochlorine pesticides (OCPs), and polycyclic aromatic hydrocarbons (PAHs) were chosen as target compounds to be quantified by Gas Chromatography-Mass Spectrometry (GC-MS), while the non-target screening was carried out by High Resolution Gas Chromatography-Mass Spectrometry (HRGC-MS). The target analysis revealed concentrations of 16 priority Polycyclic Aromatic Hydrocarbons by Environmental Protection Agency (EPA-PAHs) in the range of 29.9-269.1 ng/g; the quantification of 31 PCBs showed values from 0.54 to $15.3 \mathrm{ng} / \mathrm{g}$, identifying CB-138, 153, 180, 52, and 101 primarily; and the detected OCPs (p,p'-DDT and its metabolites) ranged between 14.5 and $63.7 \mathrm{ng} / \mathrm{g}$. The non-target screening tentatively identified 246 compounds (e.g., phthalates, antioxidants, UV-stabilizers), including endocrine disruptors, toxic and reprotoxic substances, as well as chemicals subjected to risk assessment and authorisation. The large assortment of plastic chemicals associated with MPs showed their role as a presumable source of pollutants, some of which might have high bioaccumulation potential, persistence, and toxicity.
\end{abstract}

Keywords: PCB; PAH; DDT; non-target screening; Ofanto River

\section{Introduction}

Among the critical issues related to the high presence of microplastics in the environment, their potential role as an extra substrate for the partitioning and the diffusion of hazardous compounds is of great concern.

Microplastics (MPs) can sorb and concentrate persistent organic pollutants (POPs) six times higher than that found in the marine water due to their non-polar nature and elevate surface-area-to-volume ratio [1].

POPs such as organochlorine pesticides (OCPs), polychlorobiphenyls (PCBs), and polycyclic aromatic hydrocarbons (PAHs), which have been frequently reported [2-12], were found sorbed on plastic and MPs of marine environments. Moreover, inorganic pollutants have also been found [13-15]. 
As it is known, if organisms ingest MPs, these contaminants can transfer to food webs and cause consequences to human health $[16,17]$ and ecosystems.

The sorption of hydrophobic pollutants to MPs through physical and chemical interactions is considered an essential environmental process because this will influence the mobility and bioavailability of these pollutants.

Changes such as $\mathrm{pH}$, temperature, and ionic strength of the surrounding media can influence these processes $[10,18,19]$. Hydrophobic pollutants can pass through the polymer frame, depending on the dimension of pores composing the polymeric matrix and the molecular size of the chemical compound. Consequently, small molecules with lower weights will move more quickly through a polymeric structure with larger pores.

Depending on polymer type, its density and crystallinity, the surrounding media, and the kind of pollutants present, adsorption kinetics will change [8].

Plastic products comprising microplastics generally contain a potpourri of different chemicals introduced intentionally during manufacture to improve quality (additives) that can leach into the surrounding media during their use or their spread [20-22]. Moreover, many different types of plastic additives exist, including fillers, plasticisers, stabilisers, UV-antioxidants, flame retardants, biocides, pigments, and antistatic and conductive additives, among others $[17,23]$. Progressively more types of environmental contaminants have been discovered on plastic debris $[16,24,25]$, but limited information about plastic additives as well as the nature and sources of chemicals included in MPs has been reported.

The poorness of information is partly because the elemental composition of plastic is very variable, and analytical methodologies to extract and analyse chemicals are still under development. A systematic overview of compounds and a screening of chemicals related to plastic manufacture is still missing [26].

For many years, most studies were conducted primarily on marine ecosystems. However, more recently researchers have started to expand their focus to include freshwater and terrestrial environments [27], demonstrating that rivers represent one of the principal routes for MPs to reach the oceans [28]. However, to date, few studies have considered the associations of hazardous compounds with MPs in freshwater ecosystems [29].

In light of this, our research was intended to determine chemical contaminants present in MPs collected in an Italian river in Southeast Italy (Ofanto River) in order to focus the attention on MPs as an important but often overlooked and underestimated vehicle of pollutants into the environment that can easily be ingested by organisms and be transferred in food webs. Some of these compounds originated from MPs themselves because of additives used during plastics production, while others are adsorbed from the surrounding environment. PCBs, OCPs, and PAHs have been chosen as target compounds to be quantified as environmental organic pollutants. At the same time, a qualitative non-target screening was carried out by High Resolution Gas Chromatography-Mass Spectrometry to identify a profile of emerging micropollutants carefully.

We were also interested in studying pollutants separately in a different pool of MPs. Some of the pollutants were collected from the river (environmental origin), and the others were obtained from a local plastic industry that uses virgin pre-production materials that should have fewer contaminants compared to environmental samples.

\section{Materials and Methods}

\subsection{Samples Collection}

\subsubsection{Environmental Microplastics}

Microplastics were sampled from Ofanto, the most significant river in the Apulia region (South Italy), which is $165 \mathrm{~km}$ long, with a water flow of $15 \mathrm{~m}^{3} / \mathrm{s}$ and a catchment area of $2790 \mathrm{~km}^{2}$. Five seasonal sampling campaigns were planned, aiming to monitor the variation of MP concentrations over a year. 
River surface samples were collected during February, April, October, and December 2017 and May 2018 , being taken $6 \mathrm{~km}$ from the Ofanto river mouth $\left(41^{\circ} 17^{\prime} 20.22^{\prime \prime} \mathrm{N} ; 16^{\circ} 06^{\prime} 92^{\prime \prime} \mathrm{E}\right)$.

Aiming to decrease the spatial and temporal variability [30], we sampled microplastics by 3 plankton nets $(2.5 \times 0.55 \mathrm{~m})$ of $333 \mu \mathrm{m}$ mesh size fixed in the middle of the river at the same time for 2 different time bands (11:00-13:00 and 13:00-15:00), collecting 6 replicates for each campaign for a total of 20 samples. The net was placed with a portion of it kept out of the water, filtering the first $45 \mathrm{~cm}$ of river surface. The portion of the net underwater was registered, ensuring a constant submersion for all the sampling. At the end of sampling time, we washed each net from the outside to the inside with deionised water, conveying all the sampled material (plastics and microplastics, natural debris, sediment, and other materials) into the collector tube attached to the tail of the net.

Material captured by trawls was differentiated through $5000 \mu \mathrm{m}$ and $300 \mu \mathrm{m}$ stainless steel sieves. Material retained on the $5.0 \mathrm{~mm}$ sieve was disposed of while that of the $300 \mu \mathrm{m}$ sieve was placed in a $35^{\circ} \mathrm{C}$ drying oven for $24 \mathrm{~h}$ until to sample dryness. The biggest plastic particles (5000-2000 $\mu \mathrm{m}$ ), visible to the naked eye, were randomly selected and isolated from each sample and the particles picked manually using forceps were grouped into five mean seasonal samples. The extracted microplastics were then placed in sterile plates and stored until chemical investigations.

Further details inherent sampling strategy and methodologies are described in [29].

\subsubsection{Pre-Production Microplastics}

Three main groups of pristine pre-production microplastics were also provided and analysed together to environmental samples to compare the amount of adsorbed environmental contaminants to the concentration of contaminants originating from plastics:

- $\quad$ virgin colourless polyethene (PE) pre-production pellets (size $5000 \mu \mathrm{m}$ );

- $\quad$ virgin green polyethene (PE) pre-production microparticles (size $<500 \mu \mathrm{m}$ );

- $\quad$ virgin colorless polypropylene (PP) pre-production pellets (size $5000 \mu \mathrm{m}$ ).

These virgin pre-production materials were purchased from a local plastic industry.

\subsubsection{Water Samples}

In order to compare pollutants concentration associated with MPs to contaminant concentration found in the river, we collected three replicates of water samples during the May 2018 campaign. Samples were collected in dark glass bottles and stored at $4{ }^{\circ} \mathrm{C}$ until extraction.

\subsection{Chemical Identification}

The chemical identification of the different polymers was performed by Pyrolysis-GC-MS, as reported in [29]. About 3\% of MPs (chosen on the basis of the overall morphology of particles found in samples) were hand-picked from each sample and flash-pyrolysed at $600{ }^{\circ} \mathrm{C}$, cutting $\approx 10-30 \mu \mathrm{g}$ of plastic material from each particle. The separation of pyrolysis products was performed by gas chromatography using a 7890B gas chromatograph (Agilent Technologies, Santa Clara, CA, USA) equipped with a $30 \mathrm{~m}$ Ultra ALLOY-5 capillary column (Frontier Lab, Koriyama, Japan). The temperature of the GC oven was initially set at $40{ }^{\circ} \mathrm{C}$ and held for $2 \mathrm{~min}$, secondly enhanced with $20^{\circ} \mathrm{C} \mathrm{min}-1$ until $320^{\circ} \mathrm{C}$, and finally held constant at 320 degrees for $13 \mathrm{~min}$. Identification of products was detected by high-resolution mass spectrometry using a 7200 Q-ToF (Agilent Technologies, Santa Clara, USA) operating in electron ionisation $(70 \mathrm{eV})$ and full scan $(\mathrm{m} / \mathrm{z} 50-500)$ mode. Specific products of pyrolyzation were selected as indicators for qualitative polymer analysis to characterise polymers unequivocally [29]. 


\subsubsection{Pollutants Extraction from Microplastics Samples}

The pollutant extraction procedure was selected on the basis of the physicochemical features of the target analytes to be analysed, an analysis of the extraction procedures already tested in previous studies on MPs [5,16], the costs, and the available resources.

About $250 \mathrm{mg}$ of MPs for each mean seasonal sample (environmental sample) and the same amount for the virgin samples were homogenised with diatomaceous earth forming a free-flowing powder. Then, samples were spiked with known concentrations of an internal standard solution of the labelled compound [13C12]PCB 104.

The material was extracted using $5 \mathrm{~mL}$ of n-hexane until complete submersion of the sample; this was followed by sonication (Branson 5210R-MT Ultrasonic Cleaner) for $30 \mathrm{~min}$ at $40^{\circ} \mathrm{C}$. The complete extraction process was repeated 2 more times with 2 additional $5-\mathrm{mL}$ portions of clean solvent to guarantee full extraction of analytes. The extracts were then concentrated until incipient dryness under gentle nitrogen stream (using a Caliper Life Sciences TurboVap II Concentration Workstation) and re-solubilised into $0.5 \mathrm{~mL}$ nonane. The validation of extraction procedure was checked, before determination of real samples, spiking a known amount of natives' analytes on the three main groups of virgin pre-production microplastics (previously described in Section 2.2) in order to simulate environmental samples. The recovery of the internal standard consisted of a mean of $75 \%$ (Table S4). The recoveries of the target analytes in the matrix-spiked blanks (pre-production microplastics) were acceptable, consisting of a mean of 70\% (Table S5). Further details regarding QA/QC measures are provided in Supplementary Materials.

\subsubsection{Pollutant Extraction from River Water Samples}

Every sample was spiked with noted concentrations of internal standard and extracted with a liquid-liquid method; $100 \mathrm{~mL}$ of n-hexane was added to $600 \mathrm{~mL}$ of samples and agitated for $3 \mathrm{~h}$.

For sample cleanup, $50 \mathrm{~mL}$ of extract was loaded into cartridges with $15 \mathrm{~g}$ of anhydrous sodium sulfate (BondElut Agilent) and eluted with $10 \mathrm{~mL}$ of hexane.

The extracts were then concentrated using a gentle nitrogen stream (using a Caliper Life Sciences TurboVap II Concentration Workstation) and re-solubilised into $0.5 \mathrm{~mL}$ nonane.

\subsection{Target Compound Analysis by GC-MS/MS}

All microplastic samples (Table 1) were analyzed by GC-MS/MS in order to find the following anthropogenic contaminants: 31 PCBs (CB\#18, 28, 52, 44, 95, $101,99,81,77,110,151,123,149,118,114,146,153,105,138,126,187,183$, 128, 167, 177, 156, 157, 180, 169, 170, 189), 8 OCPs (alfa-Hexa-Chloro-Cyclohexane, beta-Hexa-Chloro-Cyclohexane, gamma-Hexa-Chloro-Cyclohexane, delta-Hexa-Chloro-Cyclohexane, aldrin, p, $\mathrm{p}^{\prime}$-Dichloro-Diphenyl-Trichloroethane, $\mathrm{p}, \mathrm{p}^{\prime}$-Dichloro-Diphenyl-Dichloroethane, $\mathrm{p}, \mathrm{p}^{\prime}$-Dichloro-Diphenyl-Dichloroethylene), and 16 EPA-PAHs (acenaphthylene, acenaphthene, fluorene, phenanthrene, anthracene, fluoranthene, pyrene, benz(a)anthracene, chrysene, benzo(b)fluoranthene, benzo(k)fluoranthene, benzo(a)pyrene, indeno(123-cd)pyrene, dibenzo(ah)anthracene, and benzo-(ghi)perylene). The analyses were performed using a ThermoElectron TRACE GC Ultra coupled with a PolarisQ Ion Trap (Thermo Electron, Austin, TX, USA) mass spectrometer equipped with a Programmable Temperature Vaporizing (PTV) injector and a TriPLUSTM ${ }^{R S H} H^{T M}$ autosampler. The system was managed by Thermo Electron Xcalibur software version 1.4.1. The compound separation was achieved using an Agilent CP8944 VF- 5ms U (length 30 m, i.d. $0.25 \mathrm{~mm}$, film thickness $0.25 \mu \mathrm{m}$ ) column. More details regarding chemical standards and solvent materials, sample preparation, chemical analyses, instrumental analyses, precursor and product ions (Tables S1-S3) are described in the Supplementary Information. Total Ion Current Chromatograms for each group of pollutants are shown in Figures S1-S4. 
Table 1. Details of microplastic samples and pollutants detected for target compounds analysis by Gas Chromatography-Tandem Mass Spectrometry (GC-MS/MS).

\begin{tabular}{|c|c|c|}
\hline \multirow{3}{*}{$\begin{array}{l}\text { Pollutants } \\
\text { Analysed }\end{array}$} & PAHs & $\begin{array}{l}\text { Naphthalene, acenaphtylene, acenaphtene, fluorene, phenanthrene, anthracene, fluoranthene, } \\
\text { pyrene, benzo(a)anthracene, chrysene, benzo(b)fluoranthene, benzo(k)fluoranthene, } \\
\text { benzo(a)pyrene, indeno(123)pyrene, dibenzo(ah)anthracene, benzo(ghi)perylene }\end{array}$ \\
\hline & OCPs & Alfa-HCH, beta-HCH, gamma-HCH, delta-HCH, aldrin, p,p'-DDE, p, p'-DDD, p, p'-DDT \\
\hline & PCBs & $\begin{array}{c}18,28,52,44,95,101,99,81,77,110,151,123,149,118,114,146,153,105,138,126,187,183 \\
128,167,177,156,157,180,169,170,189\end{array}$ \\
\hline \multirow{2}{*}{$\begin{array}{l}\text { Microplastics } \\
\text { Analysed }\end{array}$} & $\begin{array}{l}\text { Pre-production } \\
\text { microplastics }\end{array}$ & $\begin{array}{l}\text { PE transparent pellets (size } 5000 \mu \mathrm{m}) \\
\text { PP transparent pellets (size } 5000 \mu \mathrm{m}) \\
\text { PE green microplastics }(\text { size } 300 \mu \mathrm{m})\end{array}$ \\
\hline & $\begin{array}{l}\text { Environmental } \\
\text { microplastics }\end{array}$ & $\begin{array}{c}\text { Polymer: PE } 77 \% \text {, PS } 13 \% \text {, PP } 10 \% \\
\text { Morphology: fragments } 50 \% \text {, pellets } 30 \% \text {, lines } 10 \% \\
\text { Color: transparent } 50 \% \text {, black } 40 \% \text {, colored } 10 \% \\
\text { Size: } 5000-1000 \mu \mathrm{m}\end{array}$ \\
\hline
\end{tabular}

\subsection{Non-Target Compounds Screening by GC-HRMS}

A non-target qualitative screening of contaminants present on environmental MPs was carried out by gas GC-HRMS analyses using a 7890B gas chromatograph (Agilent Technologies, Santa Clara, CA, USA) equipped with a $30 \mathrm{~m}$ J\&W HP-5MS (5\% phenyl methyl siloxane) capillary column with an inner diameter of $250 \mu \mathrm{m}$ and a thickness of $0.25 \mu \mathrm{m}$ coupled to a $7200 \mathrm{Q}-\mathrm{ToF}$ (Agilent Technologies, Santa Clara, CA, USA) working in electron ionisation $(70 \mathrm{eV})$ and full scan $(m / z 50-500)$ mode. The carrier gas used was helium (flow of $1 \mathrm{~mL} / \mathrm{min}$ ). The GC oven temperature program was $80^{\circ} \mathrm{C}$ (held $2 \mathrm{~min}$ )- 170 ${ }^{\circ} \mathrm{C}-30{ }^{\circ} \mathrm{C} / \mathrm{min}-320^{\circ} \mathrm{C}-12{ }^{\circ} \mathrm{C} / \mathrm{min}$ (held $10 \mathrm{~min}$ ). Two microliters were injected in the splitless mode, and EI mass spectra were analysed in the high-resolution mode ( $>25,000$ resolution).

Compound identification was performed with Agilent MassHunter Unknowns Analysis B.08.01 using the SureMass algorithm for data processing [31].

High-resolution MS profile data were extracted and converted in SureMass Chromatograms. Only peaks with a relative area greater than $1 \%$ of the largest peak were selected, and relative compounds were identified for comparison of the mass spectra with the NIST 17 library, adopting a minimum similarity criterion of $70 \%$. We refer to the latter compounds as tentatively identified as we did not use authentic standards to confirm their identity. For each chromatogram, we performed a blank subtraction.

\section{Results and Discussion}

This research allowed us to identify an extensive profile of plastic-related chemicals such as different environmental pollutants (PCBs, PAHs, OCPs) next to a variety of additives, antioxidants, degradation products, and biofilm compounds in environmental MPs collected from a river and in a different typology of virgin pre-production MPs.

The chemical characterization of environmental MPs revealed a prevalence of polyethylene (PE) $(76 \%)$ particles collected, followed by polystyrene (PS) $(12 \%)$, polypropylene (PP) $(10 \%)$, polyvinylchloride (PVC) $(0.7 \%)$, and polyurethane (TDI-PUR) $(0.35 \%)$ items. This polymer distribution was probably related to the main source of MPs in the Ofanto River linked to agricultural practices [29] that mainly use PE film for mulching [32].

\section{1. $P C B S$}

All environmental MP samples contained PCBs (expressed as the sum of 31 congeners) in the range from 0.54 to $15.3 \mathrm{ng} / \mathrm{g}$ with a mean value (calculated as the average of four sampling campaigns) of $12.89 \pm 3.4 \mathrm{ng} / \mathrm{g}$.

The most significant concentrations were observed in environmental MPs with values measured ranging from a maximum of $15.3 \mathrm{ng} / \mathrm{g}$, found in samples of May 2018, and a minimum of $7.87 \mathrm{ng} / \mathrm{g}$ observed in December 2017. 
A total of 14 PCB congeners (CB-28, 52, 77, 95, 99, 101, 110, 118, 123, 138, 149, 151, 153, 180) out of 31 investigated were measured in a concentration above the detection limit $(0.2 \mathrm{ng} / \mathrm{g})$, and 3 of these $(52,138,153)$ reached the highest concentrations (Figure 1$)$. These congeners were identified by the Stockholm Convention on Persistent Organic Pollutants (POPS) as three of the six indicator PCBs (CB-28, CB-52, CB-101, CB-138, CB-153, and CB-180) to characterise contamination by PCBs.

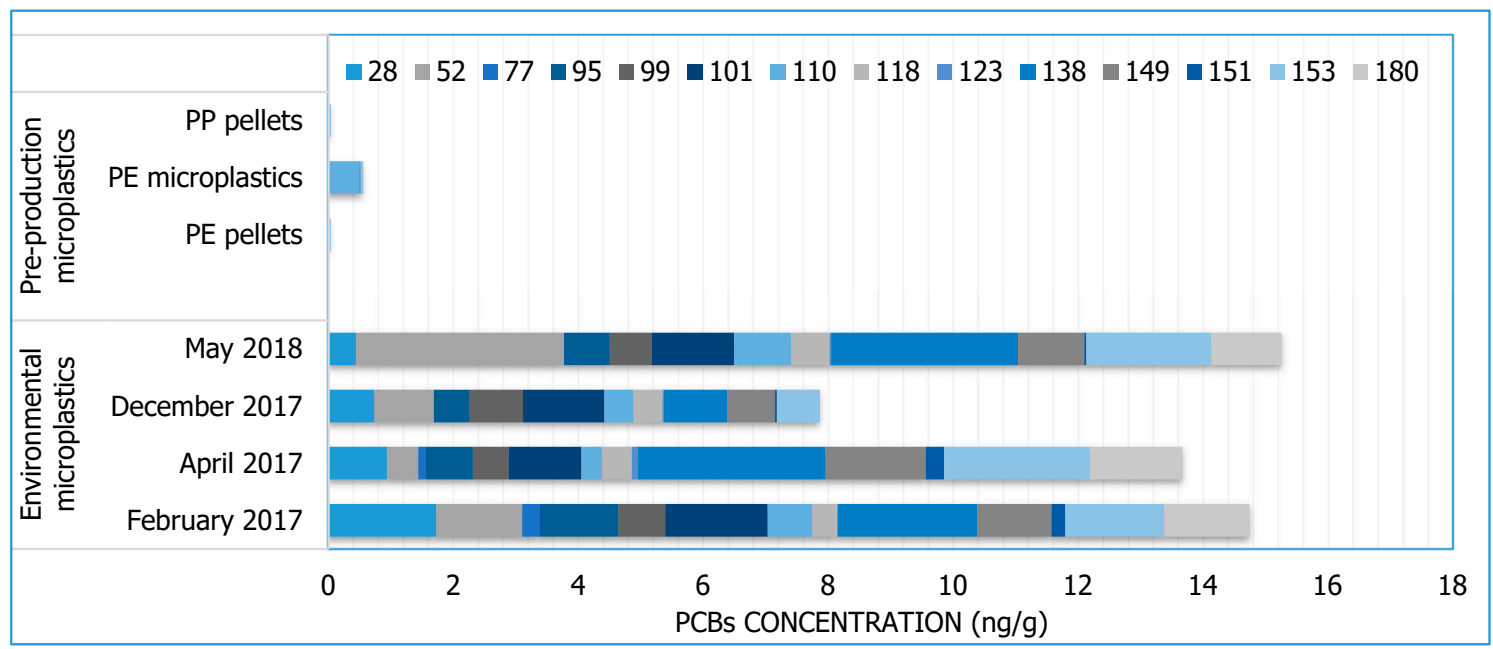

Figure 1. Concentrations of 14 polychlorobiphenyl (PCB) congeners, expressed as ng/g, registered on environmental MPs (April 2017, February 2017, December 2017, May 2018) and on virgin microplastics (MPs) (virgin polyethene (PE), virgin coloured PE, virgin polypropylene (PP)). Virgin PE and PP were colourless pellets while virgin coloured PE was green microparticles $(<500 \mu \mathrm{m})$.

The amount of total PCBs found on pre-production MPs was reasonably lower than the concentration observed on microparticles sampled from the river, and only two individual PCBs (PCB-110 and 153) were revealed as sorbed on virgin particle debris. This can be explained because PCBs are generally associated with environmental contamination and are not intentionally added during the production of plastic products (as occurs in the case of some hydrocarbons), which is why they were not detected in virgin MPs.

The concentrations of each PCB congener detected in all samples are summarised in Tables S7 and S8.

Although the ban on the use of PCBs in Italy since 1983 [33] (Directive 76/769/EEC) and their total absence revealed in water samples analysed probably due to their lipophilicity, we still found countable amounts of PCBs registered on environmental MP samples, confirming that they can concentrate, transport, and spread these pollutants from their sources to the marine environment throughout rivers.

Plastic waste and microplastics were found to be suitable substrates for concentrating POPs from areas polluted by these contaminants [2,3,34-37]. PCBs, are the most persistent among POPs. When they are in sediment or surface water, they tend to be adsorbed by hydrophobic interactions between non-polar (or slightly polar) molecules and the non-polar surface of particulate materials or sediment particles [38], with microplastic not representing an exception.

Our data are comparable to those reported by other authors on PCBs sorbed on MP debris from seawaters all over the world [39-41]. However, other authors have reported higher concentrations of PCBs than ours, up to $223,307,980,2285.8$, and $7554 \mathrm{ng} / \mathrm{g}^{-1}$ detected by $[2,39,42-44]$, respectively. This variability can be explained by a possible shorter dwelling time of our MPs into the environment, with rivers being one of the starting forms of transport for MPs to reach the oceans. Studies estimated that $80 \%$ of MP pollution in the seawater comes from the land [45]. 
Moreover, some authors related the time of permanence of microplastics into the environment to a more significant amount of organic pollutants detected on particles. This is explained by the higher level of ageing of particles that increase the sorption of chemicals [36,39].

\section{2. $\mathrm{PAHS}$}

All samples, except river water samples, were found to contain PAHs. Their quantities are reported in Figure 2. The sums of all observed PAHs (classified as priority pollutants by the United States Environmental Protection Agency, USEPA) were in the range of $29.9-269.1 \mathrm{ng} / \mathrm{g}$, with a mean value of $191.1 \pm 64.9$ for environmental samples and $57.1 \pm 23.7 \mathrm{ng} / \mathrm{g}$ for virgin MPs. The largest concentration of hydrocarbons was found in environmental MPs collected from the river in February and April 2017 (269.1 ng/g and $215.1 \mathrm{ng} / \mathrm{g}$, respectively) followed by December 2017 (160.1 ng/g) and May 2018 (120.3 ng/g). Conversely, transparent pre-production PE pellets revealed the lowest contents of PAHs for a total concentration equal to $29.9 \mathrm{ng} / \mathrm{g}$, while in coloured pre-production PE MPs $(72.8 \mathrm{ng} / \mathrm{g}$ ) and pre-production PP pellets $(68.7 \mathrm{ng} / \mathrm{g})$, PAH values were twice as high. The PAHs acenaphtylene, phenanthrene, fluoranthene, pyrene, chrysene, indeno(1,2,3,)pyrene, and benzo(G;H;I)perylene were detected in all samples (April, February, December, and May). Acenaphtene was only identified in April and February 2017, while fluorene was found in all campaigns except for the month of May. Naphthalene was present only in pre-production PE and PP pellets. The remaining PAHs were found in concentrations below the detection limits (Table S6). River water samples showed values below the detection limit for all PAHs investigated.

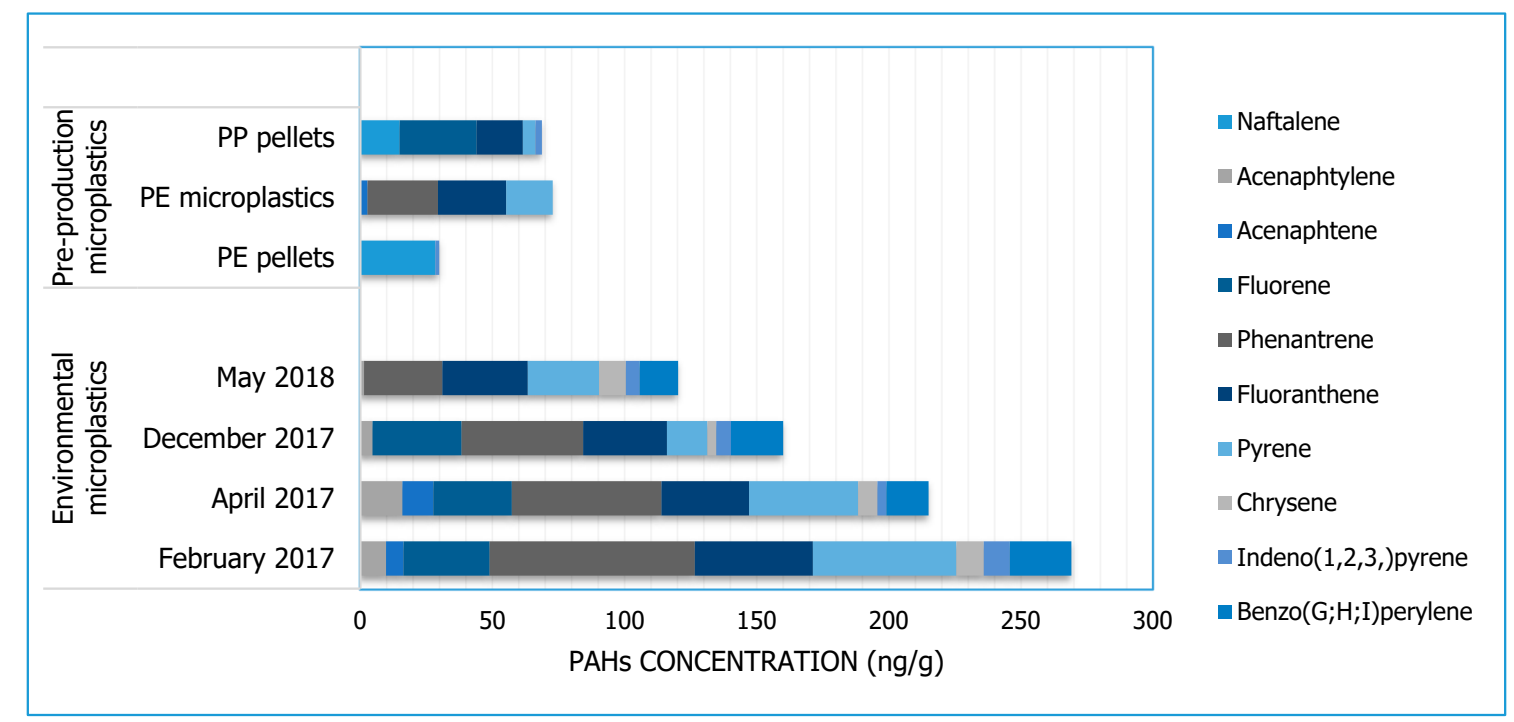

Figure 2. Concentrations of 16 EPA-PAHs, expressed as ng/g, registered on environmental MPs (April 2017, February 2017, December 2017, May 2018) and on virgin MPs (virgin PE, virgin coloured PE, virgin PP). Virgin PE and PP were colourless pellets while Virgin coloured PE was green microparticles $(<500 \mu \mathrm{m})$.

The International Pellet Watch program suggests the use of aged PE pellets as a monitoring tool for investigating the presence of pollutants adsorbed on pellets released in the marine environment [46]; the monitoring of PAHs detected the amount of hydrocarbons ranging from concentrations lower than the limit of quantification (Table S9) to values greater than 24,000 ng/g-pellets, with an average of about $3000 \mathrm{ng} / \mathrm{g}$-pellets.

Similarly, a study conducted by [47] revealed the presence of PAHs adsorbed on MPs sampled in the Feilaixia Reservoir (Guangdong Province, China), with a total concentration of 16 PAHs ranging from $282.4 \mathrm{ng} / \mathrm{g}$ to $427.3 \mathrm{ng} / \mathrm{g}$. 
These results are greater than those detected in the present study (30-270 ng/g), even if there are no Italian studies on marine pellets and limited studies on MPs of freshwater environments to be compared to.

The PAH composition found on samples analysed in the present work revealed a similar distribution of hydrocarbons in all MP environmental samples, showing a prevalence of pheanantrene followed by fluoranthene and pyrene. Although our analyses on virgin pre-production MPs were limited to only two polymers (colored/colorless PE, and PP), the results revealed the presence of different PAHs, such as naphthalene, fluoranthene, acenaphthene, pyrene, and phenanthrene, as already reported by [27].

The differences in the distribution of PAHs between environmental and virgin MPs were analysed by principal component analysis (PCA), considering eigenvectors $>0.5$ as the most significant contribution. The analysis showed that the first principal component (PC1) explained $69.7 \%$ of the data variability, while the second component (PC2) accounted for $11.8 \%$ (Figure 3 ). The differences in the distribution of PAHs created two significant groups and one smaller group. Group I was due to the presence of naftalene found only in virgin transparent PE and PP pellets, suggesting that low molecular weight hydrocarbons are less sorbed on MPs than high molecular weight compounds, probably because they are more volatile and quickly degraded [48]. Acenaphtene, Acenaphtylene and Fluorene compose Group II because found predominantly in environmental MPs than in virgin ones and Pyrene and Phenanthrene Group III due to their presence in environmental MPs and on virgin coloured PE. It is no coincidence that the physical properties of microplastics (such as colour, shape, and size) not only influence hydrocarbons concentrations but can also alter their composition on plastic [48]. Indeed, the authors of [48] demonstrated that darker pellets tend to contain higher weight hydrocarbons than lighter coloured pellets.

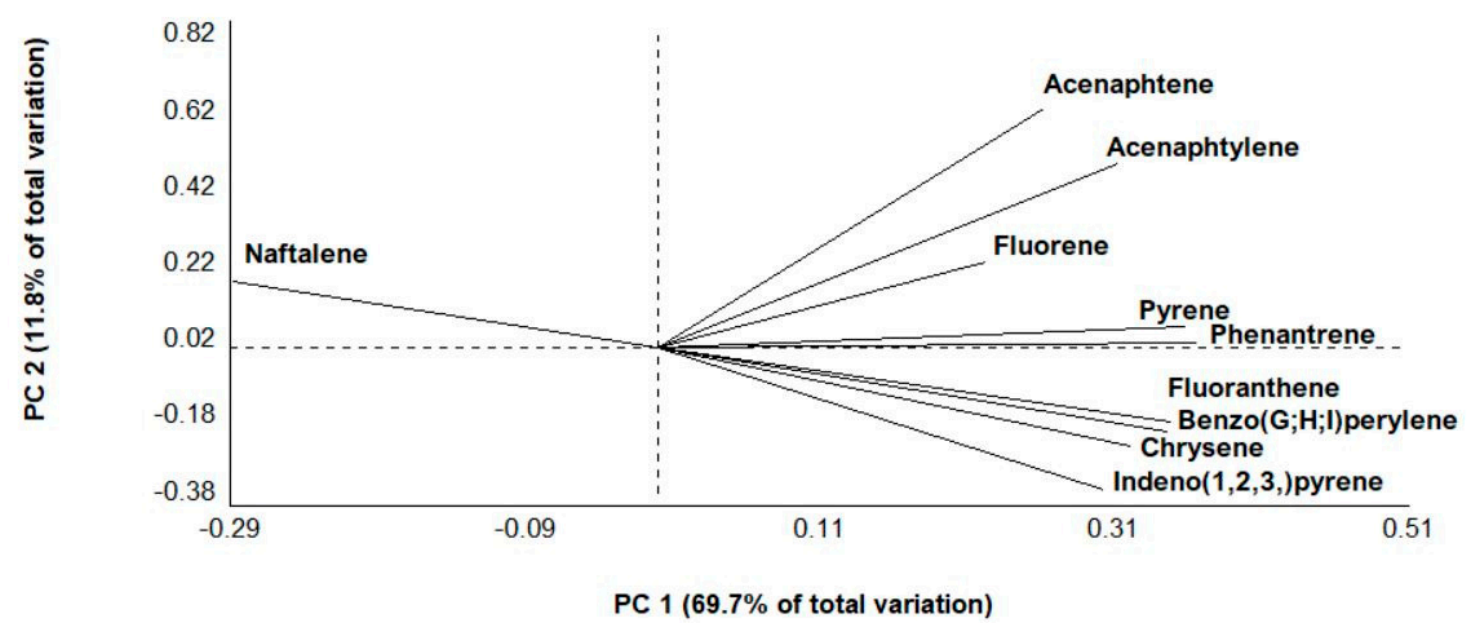

Figure 3. Principal component analysis (PCA) considering the relative higher abundance of the PAHs, grouped according to the similarity.

In previous studies, PAHs found sorbed on macro- and microplastics have been associated with petrogenic or pyrogenic sources.

Depending on specific ratios of individual or methylated PAHs, it is possible to go back to their sources such as oil seeps or combusted fuels [2,42,44,45,49].

However, attention should be paid when calculating PAH ratios for plastic, as these indices are usually calculated for source determination of PAHs in sediment [49]. Additionally to the environmental contamination (e.g., given by oil seeps or combusted fuels), an indefinite amount of PAHs found in the current study could be related to the plastic itself, as we found them both on environmental and virgin 
MP samples. Indeed, these pollutants have also been found previously by other authors on unpolluted plastic such as baby feeding bottles [50] and on virgin pellets [27].

\subsection{OCPS}

Regarding the group of organochlorine pesticides, we found that just four of them were present in environmental MPs samples (p,p-DDT, p,p-DDD, p,p-DDE, gamma-HCH).

The pollutants belonging to the DDT group (DDT, DDD, DDE) reached the most significant amount in environmental MPs, with a mean value of $37.1 \pm 22.4 \mathrm{ng} / \mathrm{g}$. The $\mathrm{p}, \mathrm{p}^{\prime}$-DDT resulted in the compound with the highest concentrations, although it reached measurable levels of 31.53 and $30.75 \mathrm{ng} / \mathrm{g}$ only in the samples collected in Ofanto River during December 2017 and May 2018 campaigns, respectively. DDTs transformation products $\mathrm{p}, \mathrm{p}^{\prime}$-DDD, and $\mathrm{p}, \mathrm{p}^{\prime}$-DDE were also detected-the former two in February 2017 (9.29 ng/g) and May 2018 (9.33 ng/g) campaigns, respectively, and the latter in all sample campaigns exceeding the Italian limit of 10ng/g fixed for soils (D.Lgs 152/2006), with values ranging from $12.2 \mathrm{ng} / \mathrm{g}$ (February 2017) to $23.7 \mathrm{ng} / \mathrm{g}$ (May 2018) (Figure 4). DDT represents the original compound released to the environment, but it often decomposes to DDD and DDE, the two main products of dechlorination of DDT by microorganisms or abiotic degradation [51,52].

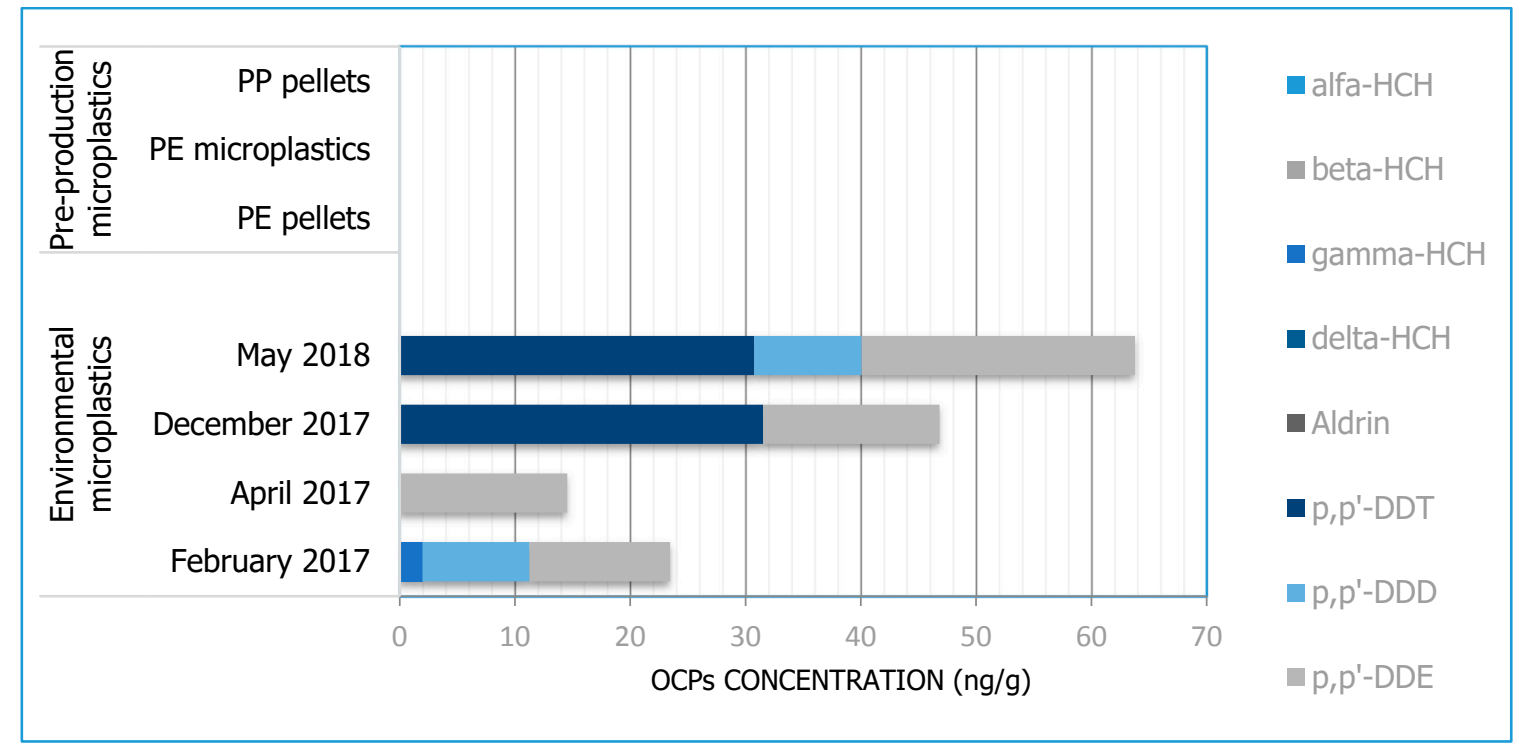

Figure 4. Concentrations of eight organochlorine pesticides (OCPs), expressed as $\mathrm{ng} / \mathrm{g}$, registered on environmental MPs (April 2017, February 2017, December 2017, May 2018), and on virgin MPs (virgin $\mathrm{PE}$, virgin coloured PE, virgin PP). Virgin PE and PP were colourless pellets while virgin coloured PE was green microparticles $(<500 \mu \mathrm{m})$.

DDE concentrations on PP MPs collected from four coastal areas in Japan revealed values ranging from $0.16 \mathrm{ng} / \mathrm{g}$ to $3.1 \mathrm{ng} / \mathrm{g}$ [1], and the International Pellets Watch reported the highest concentrations of DDTs (DDT, DDD, and DDE) in Hermosa Beach, CA, USA $(267 \mathrm{ng} / \mathrm{g})$, as well as concentrations of $4.49 \mathrm{ng} / \mathrm{g}$ and $2.43 \mathrm{ng} / \mathrm{g}$ in the Bay of Maputo, Mozambique, and South Durban, South Africa, respectively [53].

River water samples were also collected and analysed simultaneously with MP debris in order to compare the concentration of contaminants adsorbed to the concentration of pollutants found in the surrounding environment; values above the detection limit were not found in any samples.

The levels of DDT and its degradation products (DDD and DDE) detected on environmental MPs are much higher than previous values (2016-2017) recorded in surface waters and sediment during the monitoring campaigns in Ofanto River by Regional Agency for Environmental Prevention and Protection (ARPA Puglia) [54]. 
These values suggest that DDT could have been adopted as a pesticide in that area, probably in previous years when it was legal. Indeed, Apulia is well-known for its vast vineyards and olive plantations throughout the whole territory $[55,56]$; high DDT residues may originate from agricultural activities in these areas [57].

The total production of DDTs reached 3 million metric tons in the previous century, and its consumption rate in Mediterranean area achieved approximately $2000 \mathrm{t} /$ year [58].

OCPs are persistent compounds, and they have a high affinity for organic matter due to their non-polar nature; therefore, a remarkable quantity of these pesticides may remain stored in soils [59].

Increasing the input of MPs in soils due to their common terrestrial origin is of crucial importance to consider their ability to bind chemicals compared to other compartments of the soil.

The soil, then, could become a remission source because MPs can be transported by washout and surface runoff into surface waters, as well as via leaching into groundwater through irrigation $[60,61]$.

Our results show that MPs play a role in aquatic ecotoxicology as vector and concentrator of these toxic substances, becoming part of the aquatic ecosystem. Although the bioavailability of these pollutants carried by MPs has not been studied in detail, MPs considerably increase the complexity of monitoring water pollution's interaction with the entire ecosystem in different ways.

Nowadays, regulations about surface water monitoring do not consider MPs and their interactions with pollutants, which results in an emerging and complex issue that underlines the need for a deepening and revision of current legacy.

Except for gamma-HCH, which showed measurable levels only in MPs in the February 2017 campaign (Table S10), all the others pesticides investigated revealed concentrations below the detection limit in environmental MPs, such as virgin pre-production MPs and river water samples.

\subsection{Non-Target Screening}

General screening of organic compounds detected on environmental MPs (collected in April, February, and December 2017 and May 2018 campaigns) revealed the presence of a broad range of compounds (Figures S5-S8), 248 of which were identified by comparison with the spectra present in the NIST 17 library (Table S13), with a match factor $\geq 70 \%$ (Table S11). Of these, 37 were identified with a $\geq 80 \%$ confidence match factor and are summarised in Table 2.

Fifteen unknown plastic related compounds, identified for comparison by spectra of NIST 17 library with a match factor $\geq 85 \%$, were further confirmed on the basis of accurate mass measurements calculating mass errors related to the major ions observed for each compound (Table S12).

In Table 2, organics tentatively identified are sorted on the basis of the primary source of origin: plastic additives (UV stabilisers, phthalathes, antioxidants); hydrocarbons (alkanes, alkenes, substituted and cyclic hydrocarbons); intermediate; alcohol; biofilm and algae compounds.

The HRGC-MS screening identified a broad range of plastic additives. These compounds are linked to plastic production processes and are known to be added intentionally to plastic to make it soft and flexible, or they are degradation products. 
Table 2. Overview of 37 different types of compounds tentatively identified on environmental microplastic samples (April 2017, February 2017, December 2017, May 2018) by general screening. The chemicals are grouped according to their presumed source. CAS no. and NIST probability match factor \% for each compound is shown, along with molecular weight and chemical formula. Where available, common name and comments also are given; otherwise $\mathrm{n} / \mathrm{a}$ is stated.

\begin{tabular}{|c|c|c|c|c|c|c|}
\hline \multicolumn{7}{|c|}{ Environmental Microplastics } \\
\hline Category & CAS\# & Compound Name & $\begin{array}{l}\text { Match } \\
\text { Factor }\end{array}$ & Formula & $\begin{array}{l}\text { Library } \\
\text { Molecular } \\
\text { Weight }\end{array}$ & Common Name and Comments \\
\hline \multirow{10}{*}{$\begin{array}{l}\text { Hydrocarbons/ } \\
\text { alkanes and substituted } \\
\text { hydrocarbons }\end{array}$} & $544-76-3$ & Hexadecane & 96.33 & $\mathrm{C}_{16} \mathrm{H}_{34}$ & 226.266 & \multirow{10}{*}{$\begin{array}{l}n / \mathrm{a} \\
\text { Originate from the paraffin wax used as an external lubricant in PVC and other } \\
\text { polymers. Alkanes are also used as a solvent and are oligomers originating from } \\
\text { poly olefines (PP, PE, and PS) during recycling [62,63]. }\end{array}$} \\
\hline & $593-49-7$ & Heptacosane & 94.68 & $\mathrm{C}_{27} \mathrm{H}_{56}$ & 380.438 & \\
\hline & 630-04-6 & Hentriacontane & 93.29 & $\mathrm{C}_{31} \mathrm{H}_{64}$ & 436.501 & \\
\hline & $630-02-4$ & Octacosane & 91.34 & $\mathrm{C}_{28} \mathrm{H}_{58}$ & 394.454 & \\
\hline & $1186-53-4$ & Pentane, 2,2,3,4-tetramethyl- & 92.25 & $\mathrm{C}_{9} \mathrm{H}_{20}$ & 128.157 & \\
\hline & $62108-23-0$ & Decane, 2,5,6-trimethyl- & 89.72 & $\mathrm{C}_{13} \mathrm{H}_{28}$ & 184.219 & \\
\hline & $1002-43-3$ & Undecane, 3-methyl- & 89.41 & $\mathrm{C}_{12} \mathrm{H}_{26}$ & 170.203 & \\
\hline & $53366-38-4$ & Cyclopentane, (2-methylbutyl)- & 88.11 & $\mathrm{C}_{10} \mathrm{H}_{20}$ & 140.157 & \\
\hline & $17301-32-5$ & Undecane, 4,7-dimethyl- & 85.37 & $\mathrm{C}_{13} \mathrm{H}_{28}$ & 184.219 & \\
\hline & $563-16-6$ & Hexane, 3,3-dimethyl- & 82.51 & $\mathrm{C}_{8} \mathrm{H}_{18}$ & 114.141 & \\
\hline \multirow{3}{*}{$\begin{array}{l}\text { Hydrocarbons/ } \\
\text { alkenes }\end{array}$} & $629-89-0$ & 1-Octadecyne & 88.42 & $\mathrm{C}_{18} \mathrm{H}_{34}$ & 250.266 & \multirow{3}{*}{$\begin{array}{l}\mathrm{n} / \mathrm{a} \\
\text { Starter compounds for several additives and polymers or are formed as a } \\
\text { by-product in the olefin polymerisation [64]. }\end{array}$} \\
\hline & 765-13-9 & 1-Pentadecyne & 87.09 & $\mathrm{C}_{15} \mathrm{H}_{28}$ & 208.219 & \\
\hline & $74685-30-6$ & 5-Eicosene & 82.09 & $\mathrm{C}_{20} \mathrm{H}_{40}$ & 280.313 & \\
\hline \multirow{2}{*}{$\begin{array}{l}\text { Halogenated } \\
\text { hydrocarbons }\end{array}$} & $4292-19-7$ & Dodecane, 1-iodo- & 90.5 & $\mathrm{C}_{12} \mathrm{H}_{25} \mathrm{I}$ & 296.1 & \multirow{2}{*}{$\begin{array}{l}\mathrm{n} / \mathrm{a} \\
\text { Toxicity of chlorinated hydrocarbons is documented, and these compounds have } \\
\text { been considered as persistent organic pollutants }[65,66] \text {. }\end{array}$} \\
\hline & $1000406-32-0$ & Tetracosane, 1-iodo- & 85.6 & $\mathrm{C}_{24} \mathrm{H}_{49} \mathrm{I}$ & 464.288 & \\
\hline Cyclic hydrocarbons & $294-62-2$ & Cyclododecane & 90.1 & $\mathrm{C}_{12} \mathrm{H}_{24}$ & 168.188 & $\begin{array}{l}n / a \\
\text { Probably reaction products or decomposition products [66]. }\end{array}$ \\
\hline \multirow{5}{*}{$\begin{array}{l}\text { Plastic additives/UV } \\
\text { stabilisers }\end{array}$} & $1843-05-6$ & Octabenzone & 94.19 & $\mathrm{C}_{21} \mathrm{H}_{26} \mathrm{O}_{3}$ & 326.188 & $\begin{array}{c}\text { Uvinul } 3008 \\
\text { UV stabiliser } \\
\text { used to protect polymers against damage by UV [67]. }\end{array}$ \\
\hline & $5466-77-3$ & $\begin{array}{l}\text { 2-Propenoic acid, } \\
\text { 3-(4-methoxyphenyl)-, } \\
\text { 2-ethylhexyl ester }\end{array}$ & 92.45 & $\mathrm{C}_{18} \mathrm{H}_{26} \mathrm{O}_{3}$ & 290.188 & $\begin{array}{l}\mathrm{n} / \mathrm{a} \\
\text { UV-B filter, a common ingredient in sunscreen and other skincare products to } \\
\text { minimise DNA photodamage [68]. }\end{array}$ \\
\hline & $97-76-4$ & 2,4-Di-tert-butylphenol & 98.0 & $\mathrm{C}_{14} \mathrm{H}_{22} \mathrm{O}$ & 206.167 & $\mathrm{n} / \mathrm{a}$ \\
\hline & $764-42-1$ & Fumaronitrile & 95.1 & $\mathrm{C}_{4} \mathrm{H}_{2} \mathrm{~N}_{2}$ & 78.022 & $\mathrm{n} / \mathrm{a}$ \\
\hline & 2082-79-3 & $\begin{array}{l}\text { Benzenepropanoic acid, } \\
\text { 3,5-bis(1,1-dimethylethyl)-4-hydroxy-, } \\
\text { octadecyl ester }\end{array}$ & 88.13 & $\mathrm{C}_{35} \mathrm{H}_{62} \mathrm{O}_{3}$ & 530.47 & Irganox 1076 \\
\hline
\end{tabular}


Table 2. Cont

\begin{tabular}{|c|c|c|c|c|c|c|}
\hline \multicolumn{7}{|c|}{ Environmental Microplastics } \\
\hline Category & CAS\# & Compound Name & $\begin{array}{l}\text { Match } \\
\text { Factor }\end{array}$ & Formula & $\begin{array}{l}\text { Library } \\
\text { Molecular } \\
\text { Weight }\end{array}$ & Common Name and Comments \\
\hline \multirow{5}{*}{$\begin{array}{l}\text { Plastic additives/ } \\
\text { phtalathes }\end{array}$} & $84-69-5$ & $\begin{array}{l}\text { 1,2-Benzenedicarboxylic acid, } \\
\text { bis(2-methylpropyl) ester }\end{array}$ & 91.99 & $\mathrm{C}_{16} \mathrm{H}_{22} \mathrm{O}_{4}$ & 278.152 & $D i B P$ \\
\hline & $117-81-7$ & Bis(2-ethylhexyl) phthalate & 94.6 & $\mathrm{C}_{24} \mathrm{H}_{38} \mathrm{O}_{4}$ & 390.277 & $\begin{array}{c}D E H P \\
\text { reprotoxic category 2, } \mathrm{T} \text { (toxic) } \\
{[69] .}\end{array}$ \\
\hline & $84-66-2$ & Diethyl phthalate & 88.20 & $\mathrm{C}_{12} \mathrm{H}_{14} \mathrm{O}_{4}$ & 222.089 & $\begin{array}{c}D E P \\
\text { most broadly used in medicinal products [70]. }\end{array}$ \\
\hline & $84-74-2$ & Dibutyl phthalate & 87.10 & $\mathrm{C}_{16} \mathrm{H}_{22} \mathrm{O}_{4}$ & 278.152 & $\begin{array}{c}D B P \\
\text { reprotoxic category 3, } \mathrm{T} \text { (toxic), N (dangerous for the environment) [71,72]; } \\
\text { most widely used in medicinal products. }\end{array}$ \\
\hline & $28029-89-2$ & Didecan-2-yl phthalate & 87.3 & $\mathrm{C}_{28} \mathrm{H}_{46} \mathrm{O}_{4}$ & 446.34 & 1,2-Benzenedicarboxylic acid \\
\hline \multirow{4}{*}{$\begin{array}{l}\text { Plastic additives/ } \\
\text { antioxidants }\end{array}$} & $3896-11-5$ & $\begin{array}{l}\text { 2-tert-Butyl-6-(5-chloro-2H-benzotriazol- } \\
\text { 2-yl)-4-methylphenol }\end{array}$ & 89.61 & $\mathrm{C}_{17} \mathrm{H}_{18} \mathrm{ClN}_{3} \mathrm{O}$ & 315.114 & $\begin{array}{l}\text { Bumetrizole. } \\
\text { Used to slow the oxidation process of the polymers exposed to UV light [71,72] }\end{array}$ \\
\hline & $101-72-4$ & $\begin{array}{l}\text { 1,4-Benzenediamine, } \\
\mathrm{N} \text {-(1-methylethyl)-N'-phenyl- }\end{array}$ & 86.59 & $\mathrm{C}_{15} \mathrm{H}_{18} \mathrm{~N}_{2}$ & 226.147 & Santoflex IPPD \\
\hline & 95906-11-9 & $\begin{array}{l}\text { Tris(2,4-di-tert-butylphenyl) } \\
\text { phosphate }\end{array}$ & 86.12 & $\mathrm{C}_{42} \mathrm{H}_{63} \mathrm{O}_{4} \mathrm{P}$ & 662.446 & $\mathrm{n} / \mathrm{a}$ \\
\hline & $15721-78-5$ & $\begin{array}{c}\text { Benzenamine, } \\
\text { 4-(1,1,3,3-tetramethylbutyl)-N- } \\
{[4-(1,1,3,3 \text {-tetramethylbutyl)phenyl]- }}\end{array}$ & 84.4 & $\mathrm{C}_{28} \mathrm{H}_{43} \mathrm{~N}$ & 393.34 & $\mathrm{n} / \mathrm{a}$ \\
\hline Intermediate & $4337-65-9$ & $\begin{array}{l}\text { Hexanedioic acid, } \\
\text { mono(2-ethylhexyl)ester }\end{array}$ & 91.05 & $\mathrm{C}_{14} \mathrm{H}_{26} \mathrm{O}_{4}$ & 258.183 & $\mathrm{n} / \mathrm{a}$ \\
\hline \multirow{3}{*}{ Alcohols } & $10042-59-8$ & 1-Heptanol, 2-propyl- & 95.90 & $\mathrm{C}_{10} \mathrm{H}_{22} \mathrm{O}$ & 158.167 & \multirow{3}{*}{$\begin{array}{c}\text { Chemical intermediate or internal lubricant. } \\
\text { Impurities or degradation products [73-75]. } \\
\text { Screening of plastic toys and feeding utensils for babies showed the presence o } \\
\text { alcohols [76,77]. } \\
\text { Possible degradation products of plastic }[26,63,78] .\end{array}$} \\
\hline & $3913-02-8$ & 1-Octanol, 2-butyl- & 86.88 & $\mathrm{C}_{12} \mathrm{H}_{26} \mathrm{O}$ & 186.198 & \\
\hline & 54004-41-0 & 1-Pentanol, 4-methyl-2-propyl- & 84.85 & $\mathrm{C}_{9} \mathrm{H}_{20} \mathrm{O}$ & 144.151 & \\
\hline \multirow{3}{*}{$\begin{array}{l}\text { Biofilm and algae } \\
\text { compounds }\end{array}$} & $83-47-6$ & Gamma-sitosterol & 82.02 & $\mathrm{C}_{29} \mathrm{H}_{50} \mathrm{O}$ & 414.386 & $\mathrm{n} / \mathrm{a}$ \\
\hline & 201358-24-9 & 24-Noroleana-3,12-diene & 88.59 & $\mathrm{C}_{29} \mathrm{H}_{46}$ & 394.36 & $\mathrm{n} / \mathrm{a}$ \\
\hline & $502-69-2$ & 2-Pentadecanone, 6,10,14-trimethyl- & 88.43 & $\mathrm{C}_{18} \mathrm{H}_{36} \mathrm{O}$ & 268.277 & $\mathrm{n} / \mathrm{a}$ \\
\hline
\end{tabular}


Several different types of additives are used in plastic manufacture, including fillers; pigments; plasticizers; UV stabilizers; antioxidants; antiozonants; flame retardants; anti-degradants; slip stabilizers; lubricants; optical brighteners; antifog, antistatic, and conductive additives; food contact; and medical additives $[17,23,79]$.

Most of these are not chemically bound in plastics but can migrate, i.e., when chemical compounds present in the plastic structure move to its surface or to the surroundings in contact with the item.

Superficially, the compound may evaporate or be removed, e.g., washing or contact with human skin. The capability to migrate significantly influences the potential for release of compounds from plastics, and thereby the potential for exposure of consumers [79]. Both phthalates and flame retardants are substances that are well known to migrate.

The risks for human health of other plasticisers (often used as substitutes for phthalates) are not always evident, due to limited toxicological data. The level of plasticisers in plastic can reach up to $50 \%$ by weight. Thus, it makes it possible that a significant quantity can leach when plastic comes in contact with moisture. For these reasons, the entire group of plasticisers can be considered as a hazard category [63].

Plasticisers are often connected to polyvinyl chloride, although they have also been identified in printing inks and lacquers employed in the manufacturing of such other polymers [80].

Phthalates, UV-stabilizers, and antioxidants were the dominant classes of additives identified in this screening.

Among additives, phthalates, represent a category strongly related to plastic and MP debris. Indeed, they have been used in previous studies as an indicator of the presence of plastic waste in skin biopsies of fin whales of the Mediterranean region that were chronically exposed to these contaminants due to plastic and microplastic ingestion $[81,82]$.

Different phthalates were found in this screening including two (dibutyl phthalate and bis(2-ethylhexyl) phthalates of the five phthalates (bis(2-ethylhexyl) phthalate (DEHP), diisononyl phthalate (DINP), dibutyl phthalate (DBP), benzyl butyl phthalate (BBP), and di-n-octyl phthalate (DNOP)) mentioned in the Commission Decision 1999/815/EG. Phthalates have undergone risk assessment by the EU, and they have been relatively thoroughly investigated for their effects on the environment and human health as well as their use in different types of products.

Indeed, they can be endocrine disruptors, toxic to reproduction, or even suspected carcinogens (Table 2) $[17,72,83-86]$. Compared to other endocrine disruptors (EDCs), phthalates are particularly concerning because of their extensive presence, including their high levels in the environment [87-92]. Phthalates were also identified in domestic wastewater, evidencing their leeching from plastic products into the surrounding ambience $[90,91,93]$.

Dibutyl phthalate, identified in this screening, is mainly related to PP and PE products and has also been previously identified in marine debris $[63,94,95]$.

Significant quantities of bis( 2 ethylhexyl) phthalate (DEHP) have also been found in artificially aged rubber toys in comparison to low concentrations in unaged toys [96], suggesting a probable release of these substances during the weathering process.

DBP and Diethyl phthalate (DEP) are phthalates most broadly used in medicines, even if toxicological effects have been observed in animals. These findings have clinical relevance and cannot be ruled out; thus, the European Medicines Agency (EMA) will probably establish limits for the use of DBP in medicines. Furthermore, the agency will probably also establish limits for the use of DEP and Polyvinyl acetate phthalate (PVAP) in medicines [72].

The sorption of DBP and DEP on microplastics was studied in a study conducted by [97], wherein the authors demonstrated that the hydrophobic interaction and ionic strength dominated the partition, with the sorption of DBP being almost 100 times higher than DEP. Moreover, solution $\mathrm{pH}$ and natural organic matter had small impacts on phthalate sorption by microplastics, indicating that microplastics could accumulate them in different aquatic environments. 
Because of the potential risk of DEHP and DBP [98-101] and the potential hazard of other phthalates, this group is considered a hazard category [63].

Together with phthalates, several types of antioxidants were also found in the environmental microplastic samples. They are compounds that work to slow down the oxidation cycle, usually by scavenging free radicals to inhibit the oxidative degradation of plastics. Oxidation during mixing or manufacture can cause problems such as loss of strength, breakdown, or discolouration; oxidation can also verify in the final product causing discoloration; scratching; and loss of strength, flexibility, stiffness, or gloss [63].

Many antioxidants can be used to prevent the ageing of plastic, such as phenolic antioxidants, organophosphorus compounds, and hindered amines and thioesters [102]. In this screening, bumetrizole, 1,4-benzenediamine, N-(1-methylethyl)-N'-phenyl- (commercially known as Santoflex IPPD) and Tris (2,4-di-tert-butylphenyl) phosphate (Irgafos 168) were found. Bumetrizole is generally used to slow the oxidation process of the polymer exposed to UV light. It preferentially degrades itself and helps in this way to stabilise the polymer [71,72]. It does not have high toxicity, but it does not allow for contact with fatty foods.

Antioxidants are used in little quantities up to $2 \% w / w(20,000 \mathrm{mg} / \mathrm{kg}$ or $\mathrm{ppm})$ in almost all commercial polymers.

Among additives, stabilisers were also detected in this screening. Generally, stabilisers are used to prevent plastic's degradation (e.g., by temperature, light, UV light, oxygen, and other types of weathering), thus prolonging the lifetime of the products.

Heat stabilisers have a role in protecting synthetic polymers during the thermal production process to avoid product decomposition and to protect against heat in long-term use at high temperatures.

UV stabilisers are used to prevent or protect degradation of plastics from ultraviolet rays by absorbing the harmful UV light that changes the physical and optical properties of the polymer, protecting the plastic against discolouration, cracking, brittleness, or other loss of desirable physical properties. The stabilisers act in such a way that they will be decomposed instead of the plastic polymers $[79,103]$. This behaviour means that for mechanical recycling of plastics, it is necessary to add further stabilisers for protection against degradation in the newly recycled plastic products [79].

Typical UV stabilizers are benzophenones, hindered amines, and benzotriazole. Salicylate esters, cyanoacrylates, and benzylidene are also used, but are not as effective [104]. The following six UV stabilisers were identified in extracted samples: octabenzone (Uvinul 3008); 2-propenoic acid, 3-(4-methoxyphenyl)-, 2-ethylhexyl ester; benzophenone; phenol, 2-(5-chloro-2H-benzotriazol-2-yl)-4,6-bis(1,1-dimethylethyl)-; 2,4-di-tert-butylphenol; and benzenepropanoic acid, 3,5-bis(1,1-dimethylethyl)-4-hydroxy-octadecyl ester (Irganox 1076).

Many additives such as benzotriazole UV stabilisers and phenolic antioxidants are expected to have $\log$ Kow (log n-octanol/water partition coefficient) values between 5 and 8 and have the potential for bioaccumulation. Although field observations are lacking information related to environmental partitioning of these chemicals, their metabolic transformation, and biodegradability, on the basis of estimated high partition coefficients and low biodegradability, it is possible to hypothesise their concentration through the marine food chain.

Experimental studies of phenolic antioxidants and benzotriazole UV stabilisers in sediments and fish partly support this hypothesis [105-107], even if it is not ensured that plastic waste is a relevant source of these compounds in the environment $[79,108]$. Octabenzone is a UV absorber/screener used to protect polymers (e.g., polyethene, polypropylene, polyvinylchloride) against damage by UV light and is subjected to risk assessment and authorisation before use [69]. Octyl methoxycinnamate (trade names Eusolex 2292 and Uvinul MC80) is a UV absorber and also a Federal Food, Drug, and Cosmetic Act (FDA) category 1 sunscreen, approved worldwide at concentrations up to $10 \%$, and is the most frequently used sun screening agent. 


\section{Conclusions}

The present data represent a detailed survey of pollutants investigated on different types of MP samples-some collected in a freshwater environment, others provided by a plastic industry as virgin materials. This research provides one of the few datasets of chemicals associated with MPs in a freshwater ecosystem. Almost always, environmental MPs showed greater values of pollutants than virgin ones. PAHs resulted in the category with higher concentrations, with a mean value of $191.1 \pm 64.9$ for environmental samples and $57.1 \pm 23.7 \mathrm{ng} / \mathrm{g}$ for virgin MPs. The DDT group was detected only on environmental MPs, showing concentrations higher than the Italian regulatory limit set for soils. Similarly, PCBs were detected almost exclusively in environmental samples, with concentrations ranging from 7.9 to $15.3 \mathrm{ng} / \mathrm{g}$.

In general, lower concentrations of PCBs, PAHs, and OCPs were detected in our MPs collected in a freshwater ecosystem in comparison with contaminants found sorbed on samples collected in marine environments in previous studies. This is probably explained because rivers are one of the starter pathways of MPs, implying a briefer time of permanence in the freshwater environment with respect to the oceanic zones that are, on the contrary, the final receptors. The consequence is a different level of pollution between the two environments given by the lower level of ageing of MPs collected in rivers that is known to be a factor responsible for the sorption of pollutants.

The non-target screening of freshwater MPs provided evidence of a pool of chemicals associated with MPs, and more than 200 organic substances have been identified, (UV stabilisers, phthalates, antioxidants, hydrocarbons, lubricants, intermediates, biocides, biofilm compounds, and degradation products), pointing out that MPs represent a multifaceted stressor for ecosystems. These results underscore the role of MPs as a multifaceted stressor for ecosystems because on the one hand they are themselves a source of a broad range of chemicals used as additives during plastic production, and on the other hand pollutants belonging from other sources and spread in the environment are sorbed on microplastics.

Supplementary Materials: The following are available online at http://www.mdpi.com/2305-6304/8/4/100/s1, Figure S1: GC-MS total ion chromatograms (TICs) of PAHs related to microplastic extract of the April 2017 campaign. Figure S2: GC-MS total ion chromatograms (TICs) of PAHs related to microplastic extract of the February 2017 campaign. Figure S3: GC-MS total ion chromatograms (TICs) of PAHs related to microplastic extract of the December 2017 campaign. Figure S4: GC-MS total ion chromatograms (TIC) of PAHs related to microplastic extract of the May 2018 campaign. Table S1: Lists of PCB congeners and their precursor and product ions used for the MS/MS method for GC-MS analysis. ${ }^{*}$ Compound is an internal standard. Table S2: lists of OCPs and their precursor and product ions used for the MS/MS method for GC-MS analysis. Table S3: Lists of PAHs their precursor ions used for the MS/MS method for GC-MS analysis. Table S4:PCB recoveries calculated for each sample using [13C12]PCB 104 as an internal standard. Table S5: PAH and OCP recoveries calculated on spiked matrix blanks. Table S6: Limit of detection (LOD) values for the validated methods, in ng/g $\mathrm{g}^{-1}$ plastic. Table S7: Concentrations of 16 PCBs congeners, expressed as ng/g, found on environmental microplastic samples (April 2017, February 2017, December 2017, May 2018), and on virgin pre-production microplastics (virgin PE, virgin colored PE, virgin PP). Virgin PE and PP were colorless pellets while Virgin colored PE was green microparticles $(<500 \mu \mathrm{m})$. Congeners indicated in red are the dioxin-like ones. Table S8: Concentrations of 16 PCB congeners, expressed as ng/g, found on environmental microplastic samples (April 2017, February 2017, December 2017, May 2018), and on virgin pre-production microplastics (virgin PE, virgin colored PE, virgin PP). Virgin PE and PP were colorless pellets while virgin colored PE was green microparticles $(<500 \mu \mathrm{m})$. Congeners indicated in red are the dioxin-like ones. Table S9: Concentrations of 16 EPA-PAHs, expressed as ng/g, found on environmental microplastic samples (April 2017, February 2017, December 2017, May 2018) and on virgin pre-production microplastics (virgin PE, virgin colored PE, virgin PP). Virgin PE and PP were colorless pellets while virgin colored PE was green microparticles $(<500 \mu \mathrm{m})$. Table S10: Concentrations of eight OCPs, expressed as ng/g, found on environmental microplastic samples (April 2017, February 2017, December 2017, May 2018) and on virgin pre-production microplastics (virgin PE, virgin colored PE, virgin PP). Virgin PE and $\mathrm{PP}$ were colorless pellets while virgin colored PE was green microparticles $(<500 \mu \mathrm{m})$. Table S11: Overview of 248 different types of compounds hypothetically identified on environmental microplastic samples (April 2017, February 2017, December 2017, May 2018) by the general screening. The CAS no., NIST probability match factor \%, molecular weight, and chemical formula of each compound are also given in the table. Table S12: Accurate mass measurements and elemental compositions of compounds found on microplastic and their product ions using HRGC-MS analysis. Table S13: Comparison of high-resolution spectra of 15 hypothetically identified compounds by spectra of NIST 17 library. 
Author Contributions: C.C.: conceptualiszation, methodology, formal analysis, writing-original draft, writing-review and editing. G.D.: methodology, validation, instrumental analysis, writing-review and editing. C.M.: formal analysis, data elaboration, writing — review and editing, project administration, funding acquisition. G.B.: methodology, instrumental analysis, writing - review and editing. V.F.U.: project administration, resources, funding acquisition, supervision. All authors have read and agreed to the published version of the manuscript.

Funding: This work was supported by the project "MICROPLASMA-MIcro and maCRO PLAStic pollution Monitoring with Advanced technologies" POR Puglia FESR-ESF 2014-2020 INNOLABS “-Code P0XST06.

Acknowledgments: The authors want to thank Paolo Lovascio and Charmaigne Pumihic for their precious help and support in language revision.

Conflicts of Interest: The authors declare that they have no known competing for financial interests or personal relationships that could have appeared to influence the work reported in this paper.

\section{References}

1. Mato, Y.; Isobe, T.; Takada, H.; Kanehiro, H.; Ohtake, C.; Kaminuma, T. Plastic Resin Pellets as a Transport Medium for Toxic Chemicals in the Marine Environment. Environ. Sci. Technol. 2001, 35, 318-324. [CrossRef]

2. Rios, L.M.; Moore, C.; Jones, P.R. Persistent organic pollutants carried by synthetic polymers in the ocean environment. Mar. Pollut. Bull. 2007, 54, 1230-1237. [CrossRef]

3. Rios, L.M.; Jones, P.R.; Moore, C.J.; Narayan, U.V. Quantitation of persistent organic pollutants adsorbed on plastic debris from the Northern Pacific Gyre's "eastern garbage patch". J. Environ. Monit. 2010, 12, 2226-2236. [CrossRef]

4. Ryan, P.G.; Bouwman, H.; Moloney, C.L.; Yuyama, M.; Takada, H. Long-term decreases in persistent organic pollutants in South African coastal waters detected from beached polyethylene pellets. Mar. Pollut. Bull. 2012, 64, 2756-2760. [CrossRef]

5. Van, A.; Rochman, C.M.; Flores, E.M.; Hill, K.L.; Vargas, E.; Vargas, S.A.; Hoh, E. Persistent organic pollutants in plastic marine debris found on beaches in San Diego, California. Chemosphere 2012, 86, 258-263. [CrossRef]

6. Eriksson, C.; Burton, H.; Fitch, S.; Schulz, M.; van den Hoff, J. Daily accumulation rates of marine debris on sub-Antarctic island beaches. Mar. Pollut. Bull. 2013, 66, 199-208. [CrossRef]

7. Hartmann, N.B.; Rist, S.; Bodin, J.; Jensen, L.H.S.; Schmidt, S.N.; Mayer, P.; Meibom, A.; Baun, A. Microplastics as vectors for environmental contaminants: Exploring sorption, desorption, and transfer to biota. Integr. Environ. Assess. Manag. 2017, 13, 488-493. [CrossRef]

8. Wagner, M.; Lambert, S. Freshwater microplastics. Emerging environmental contaminants? In The Handbook of Environmental Chemistry; Barceló, D., Kostianoy, A.G., Eds.; Springer Open: Cham, Switzerland, 2018; Volume 58, pp. 1-16.

9. León, V.M.; García, I.; González, E.; Samper, R.; Fernández-González, V.; Muniategui-Lorenzo, S. Potential transfer of organic pollutants from littoral plastics debris to the marine environment. Environ. Pollut. 2018, 236, 442-453. [CrossRef]

10. Wang, F.; Wong, C.S.; Chen, D.; Lu, X.; Wang, F.; Zeng, E.Y. Interaction of toxic chemicals with microplastics: A critical review. Water Res. 2018, 139, 208-219. [CrossRef]

11. León, V.M.; García-Agüera, I.; Moltó, V.; Fernández-González, V.; Llorca-Pérez, L.; Andrade, J.M.; Muniategui-Lorenzo, S.; Campillo, J.A. PAHs, pesticides, personal care products and plastic additives in plastic debris from Spanish Mediterranean beaches. Sci. Total. Environ. 2019, 670, 672-684. [CrossRef]

12. Gorman, D.; Moreira, F.T.; Turra, A.; Fontenelle, F.R.; Combi, T.; Bícego, M.C.; Martins, C.D.C. Organic contamination of beached plastic pellets in the South Atlantic: Risk assessments can benefit by considering spatial gradients. Chemosphere 2019, 223, 608-615. [CrossRef]

13. Graca, B.; Bełdowska, M.; Wrzesień, P.; Zgrundo, A. Styrofoam debris as a potential carrier of mercury within ecosystems. Environ. Sci. Pollut. Res. 2014, 21, 2263-2271. [CrossRef]

14. Holmes, L.A. Interactions of Trace Metals with Plastic Production Pellets in the Marine Environment. Ph.D. Thesis, University of Plymouth, Plymouth, UK, 2013.

15. Holmes, L.A.; Turner, A.; Thompson, R.C. Interactions between trace metals and plastic production pellets under estuarine conditions. Mar. Chem. 2014, 167, 25-32. [CrossRef]

16. Hong, S.H.; Shim, W.J.; Hong, L. Methods of analysing chemicals associated with microplastics: A review. Anal. Methods 2017, 9, 1361-1368. [CrossRef] 
17. Campanale, C.; Massarelli, C.; Savino, I.; Locaputo, V.; Uricchio, A.V.F. A Detailed Review Study on Potential Effects of Microplastics and Additives of Concern on Human Health. Int. J. Environ. Res. Public Health 2020, 17, 1212. [CrossRef]

18. Koelmans, A.A.; Bakir, A.; Burton, G.A.; Janssen, C.R. Microplastic as a Vector for Chemicals in the Aquatic Environment: Critical Review and Model-Supported Reinterpretation of Empirical Studies. Environ. Sci. Technol. 2016, 50, 3315-3326. [CrossRef]

19. Ma, Y.; Huang, A.; Cao, S.; Sun, F.; Wang, L.; Guo, H.; Ji, R. Effects of nanoplastics and microplastics on toxicity, bioaccumulation, and environmental fate of phenanthrene in fresh water. Environ. Pollut. 2016, 219, 166-173. [CrossRef]

20. Luo, H.; Xiang, Y.; He, D.; Li, Y.; Zhao, Y.; Wang, S.; Pan, X. Leaching behavior of fluorescent additives from microplastics and the toxicity of leachate to Chlorella vulgaris. Sci. Total. Environ. 2019, 678, 1-9. [CrossRef]

21. Chen, Q.; Allgeier, A.; Yin, D.; Hollert, H. Leaching of endocrine disrupting chemicals from marine microplastics and mesoplastics under common life stress conditions. Environ. Int. 2019, 130, 104938. [CrossRef]

22. Luo, H.; Li, Y.; Zhao, Y.; Xiang, Y.; He, D.; Pan, X. Effects of accelerated aging on characteristics, leaching, and toxicity of commercial lead chromate pigmented microplastics. Environ. Pollut. 2020, 257, 113475. [CrossRef]

23. Murphy, J. Additives for Plastics Handbook, 2nd ed.; Elsevier Science Ltd.: Oxford, UK; New York, NY, USA; Tokyo, Japan, 2001; pp. 30-60.

24. Zimmermann, L.; Dierkes, G.; Ternes, T.A.; Völker, C.; Wagner, M. Benchmarking the in Vitro Toxicity and Chemical Composition of Plastic Consumer Products. Environ. Sci. Technol. 2019, 53, 11467-11477. [CrossRef]

25. Hahladakis, J.N.; Velis, C.A.; Weber, R.; Iacovidou, E.; Purnell, P. An overview of chemical additives present in plastics: Migration, release, fate and environmental impact during their use, disposal and recycling. J. Hazard. Mater. 2018, 344, 179-199. [CrossRef]

26. Gauquie, J.; Devriese, L.I.; Robbens, J.; De Witte, B. A qualitative screening and quantitative measurement of organic contaminants on different types of marine plastic debris. Chemosphere 2015, 138, 348-356. [CrossRef]

27. Burns, E.E.; Boxall, A.B.A. Microplastics in the aquatic environment: Evidence for or against adverse impacts and major knowledge gaps. Environ. Toxicol. Chem. 2018, 37, 2776-2796. [CrossRef]

28. Campanale, C.; Stock, F.; Massarelli, C.; Kochleus, C.; Bagnuolo, G.; Reifferscheid, G.; Uricchio, V.F. Microplastics and their possible sources: The example of Ofanto river in southeast Italy. Environ. Pollut. 2020, 258, 113284. [CrossRef]

29. Mendoza, L.M.R.; Balcer, M. Association of hazardous compounds with microplastics in freshwater ecosystems. In Microplastics in Water and Wastewater; IWA Publishing: London, UK, 2019; pp. 15-25. [CrossRef]

30. Campanale, C.; Savino, I.; Pojar, I.; Massarelli, C.; Uricchio, V.F. A Practical Overview of Methodologies for Sampling and Analysis of Microplastics in Riverine Environments. Sustainability 2020, 12, 6755. [CrossRef]

31. Agilent SureMass, Agilent Technologies Technical Overview, Publication Number 5991-8048EN (2017); Agilent Technologies: Wood Dale, IL, USA, 2017.

32. Plastics-The Facts 2019. An Analysis of European Plastics Production, Demand and Waste Data; PlasticsEurope, Carbon Neutral Printing-Natureoffice: Wiesbaden, Germany, 2019.

33. Council Directive 76/769/EEC of 27 July 1976 on the Approximation of the Laws, Regulations and Administrative Provisions of the Member States Relating to Restrictions on the Marketing and Use of Certain Dangerous Substances and Preparations; Official Journal of the European Communities: Bruxelles, Belgium, 1976.

34. Endo, S.; Takizawa, R.; Okuda, K.; Takada, H.; Chiba, K.; Kanehiro, H.; Ogi, H.; Yamashita, R.; Date, T. Concentration of polychlorinated biphenyls (PCBs) in beached resin pellets: Variability among individual particles and regional differences. Mar. Pollut. Bull. 2005, 50, 1103-1114. [CrossRef]

35. Engler, R.E. The Complex Interaction between Marine Debris and Toxic Chemicals in the Ocean. Environ. Sci. Technol. 2012, 46, 12302-12315. [CrossRef]

36. Bakir, A.; Rowland, S.J.; Thompson, R.C. Transport of persistent organic pollutants by microplastics in estuarine conditions. Estuarine Coast. Shelf Sci. 2014, 140, 14-21. [CrossRef]

37. Camacho, M.; Herrera, A.; Gomez, M.; Acosta-Dacal, A.; Martínez, I.; Henríquez-Hernández, L.A.; Luzardo, O.P. Organic pollutants in marine plastic debris from Canary Islands beaches. Sci. Total. Environ. 2019, 662, 22-31. [CrossRef] 
38. Tourinho, P.S.; Kočí, V.; Loureiro, S.; Van Gestel, C.A.M. Partitioning of chemical contaminants to microplastics: Sorption mechanisms, environmental distribution and effects on toxicity and bioaccumulation. Environ. Pollut. 2019, 252, 1246-1256. [CrossRef]

39. Frias, J.; Sobral, P.; Ferreira, A. Organic pollutants in microplastics from two beaches of the Portuguese coast. Mar. Pollut. Bull. 2010, 60, 1988-1992. [CrossRef]

40. Hirai, H.; Takada, H.; Ogata, Y.; Yamashita, R.; Mizukawa, K.; Saha, M.; Kwan, C.; Moore, C.; Gray, H.; Laursen, D.; et al. Organic micropollutants in marine plastics debris from the open ocean and remote and urban beaches. Mar. Pollut. Bull. 2011, 62, 1683-1692. [CrossRef]

41. Jayasiri, H.B.; Purushothaman, C.S.; Vennila, A. Bimonthly variability of persistent organochlorines in plastic pellets from four beaches in Mumbai coast, India. Environ. Monit. Assess. 2015, 187, 469. [CrossRef]

42. Antunes, J.C.; Frias, J.G.L.; Micaelo, A.C.; Sobral, P. Resin pellets from beaches of the Portuguese coast and adsorbed persistent organic pollutants. Estuarine Coast. Shelf Sci. 2013, 130, 62-69. [CrossRef]

43. Mizukawa, K.; Takada, H.; Ito, M.; Geok, Y.B.; Hosoda, J.; Yamashita, R.; Saha, M.; Suzuki, S.; Miguez, C.; Frias, J.; et al. Monitoring of a wide range of organic micropollutants on the Portuguese coast using plastic resin pellets. Mar. Pollut. Bull. 2013, 70, 296-302. [CrossRef]

44. Taniguchi, S.; Colabuono, F.I.; Dias, P.S.; Oliveira, R.; Fisner, M.; Turra, A.; Izar, G.M.; Abessa, D.M.; Saha, M.; Hosoda, J.; et al. Spatial variability in persistent organic pollutants and polycyclic aromatic hydrocarbons found in beach-stranded pellets along the coast of the state of São Paulo, southeastern Brazil. Mar. Pollut. Bull. 2016, 106, 87-94. [CrossRef]

45. Rochman, C.M. Microplastics research-From sink to source. Science 2018, 360, 28-29. [CrossRef]

46. International Pellet Watch. Available online: http://www.pelletwatch.org (accessed on 10 July 2020).

47. Tan, X.; Yu, X.; Cai, L.; Wang, J.; Peng, J. Microplastics and associated PAHs in surface water from the Feilaixia Reservoir in the Beijiang River, China. Chemosphere 2019, 221, 834-840. [CrossRef]

48. Fisner, M.; Majer, A.; Taniguchi, S.; Bícego, M.C.; Turra, A.; Gorman, D. Colour spectrum and resin-type determine the concentration and composition of Polycyclic Aromatic Hydrocarbons (PAHs) in plastic pellets. Mar. Pollut. Bull. 2017, 122, 323-330. [CrossRef]

49. Fisner, M.; Taniguchi, S.; Moreira, F.; Bícego, M.C.; Turra, A. Polycyclic aromatic hydrocarbons (PAHs) in plastic pellets: Variability in the concentration and composition at different sediment depths in a sandy beach. Mar. Pollut. Bull. 2013, 70, 219-226. [CrossRef]

50. Simoneau, C.; Van Den Eede, L.; Valzacchi, S. Identification and quantification of the migration of chemicals from plastic baby bottles used as substitutes for polycarbonate. Food Addit. Contam. Part A 2011, 29, 469-480. [CrossRef]

51. Pfaender, F.K.; Alexander, M. Extensive microbial degradation of DDT in vitro and DDT metabolism by natural communities. J. Agric. Food Chem. 1972, 20, 842-846. [CrossRef]

52. Mackay, D.; Shiu, W.Y.; Ma, K.C. Illustrated handbook of physical—Chemical properties and environmental fate for organic compounds. Lewis Publishers, Chelsea magna. Environ. Monit. Assess. 1992, 187, 1-14.

53. Ogata, Y.; Takada, H.; Mizukawa, K.; Hirai, H.; Iwasa, S.; Endo, S.; Mato, Y.; Saha, M.; Okuda, K.; Nakashima, A.; et al. International Pellet Watch: Global monitoring of persistent organic pollutants (POPs) in coastal waters. 1. Initial phase data on PCBs, DDTs, and HCHs. Mar. Pollut. Bull. 2009, 58, 1437-1446. [CrossRef]

54. ARPA (Regional Agency for Environmental Prevention and Protection) 2016. Monitoraggio Qualitativo dei Corpi Idrici Superficiali per il Triennio 2016-2018. Available online: www.arpa.puglia.it|T1〉 guilsinglrightdocument_library \T1 \guilsinglrightget_file (accessed on 8 September 2020).

55. Costantini, E.A.C.; Dazzi, C. The Soils of Italy; Springer Science \& Business Media: Dordrecht, The Netherlands, 2013.

56. ISPRA. Audizione dell'Istituto Superiore per la Protezione e la Ricerca Ambientale (ISPRA) presso la Commissione Agricoltura, congiuntamente con la Commissione Ambiente, della Camera sul consumo di suolo, Audizione; ISPRA Istituto Superiore per la Protezione e la Ricerca Ambientale: Rome, Italy, 2014.

57. Thiombane, M.; Petrik, A.; Di Bonito, M.; Albanese, S.; Zuzolo, D.; Cicchella, D.; Lima, A.; Qu, C.; Qi, S.-H.; De Vivo, B. Status, sources and contamination levels of organochlorine pesticide residues in urban and agricultural areas: A preliminary review in central-southern Italian soils. Environ. Sci. Pollut. Res. 2018, 25, 26361-26382. [CrossRef]

58. Bacci, E. Ecotoxicology of Organic Contaminants; CRC Press: Boca Raton, FL, USA, 1993. 
59. Zhang, A.; Chen, Z.; Ahrens, L.; Liu, W.; Li, Y.-F. Concentrations of DDTs and Enantiomeric Fractions of Chiral DDTs in Agricultural Soils from Zhejiang Province, China, and Correlations with Total Organic Carbon and pH. J. Agric. Food Chem. 2012, 60, 8294-8301. [CrossRef]

60. Montuori, P.; Cirillo, T.; Fasano, E.; Nardone, A.; Esposito, F.; Triassi, M. Spatial distribution and partitioning of polychlorinated biphenyl and organochlorine pesticide in water and sediment from Sarno River and Estuary, Southern Italy. Environ. Sci. Pollut. Res. 2014, 21, 5023-5035. [CrossRef]

61. Qu, C.; Albanese, S.; Chen, W.; Lima, A.; Doherty, A.L.; Piccolo, A.; Arienzo, M.; Qi, S.; De Vivo, B. The status of organochlorine pesticide contamination in the soils of the Campanian Plain, southern Italy, and correlations with soil properties and cancer risk. Environ. Pollut. 2016, 216, 500-511. [CrossRef]

62. Rashid, M.M.; Sarker, M. Waste polyethylene terephthalate (PETE) and polystyrene (PS) into fuel. Int. J. Sci. Technol. Res. 2013, 2, 176-189.

63. Rani, M.; Shim, W.J.; Han, G.M.; Jang, M.; Al-Odaini, N.A.; Song, Y.K.; Hong, S.H. Qualitative Analysis of Additives in Plastic Marine Debris and Its New Products. Arch. Environ. Contam. Toxicol. 2015, 69, 352-366. [CrossRef] [PubMed]

64. Screening of Plastic Toys for Chemical Composition and Hazards-Market Surveillance in the Netherlands; Report ND05o610/01; Food and Safety Authority (VWA): Zutphen, The Netherlands, 2005.

65. Rogan, W.J.; Gladen, B.C. Neurotoxicology of PCBs and related compounds. Neurotoxicology 1992, 13, 27-36. [PubMed]

66. De Duffard, A.M.E.; Duffard, R. Behavioral toxicology, risk assessment, and chlorinated hydrocarbons. Environ. Heal. Perspect. 1996, 104, 353-360. [CrossRef]

67. Commission Regulation (EU) No 10/2011 of 14 January 2011 on Plastic Materials and Articles Intended to Come into Contact with Food Text with EEA Relevance; Official Journal of the European Communities: Bruxelles, Belgium, 2011.

68. Detoni, C.B.; Paese, K.; Beck, R.C.R.; Pohlmann, A.R.; Guterres, S.S. Nanosized and Nanoencapsulated Sunscreens. In Nanocosmetisc and Nanomedicines; Beck, R., Guterres, S., Pohlmann, A., Eds.; Springer: Berlin/Heidelberg, Germany, 2011; pp. 333-362. [CrossRef]

69. Council Directive 67/548/EEC of 27 June 1967 on the Approximation of Laws, Regulations and Administrative Provisions Relating to the Classification, Packaging and Labelling of Dangerous Substances; Official Journal of the European Communities: Bruxelles, Belgium, 1967.

70. Phthalate Strategy; Environmental Project No. 1488; The Danish EPA: Copenhagen, Denmark, 2013; ISBN no.978-87-93026-22-3.

71. Lau, O.-W.; Wong, S.-K. Contamination in food from packaging material. J. Chromatogr. A 2000, 882, $255-270$. [CrossRef]

72. Lahimer, M.C.; Ayed, N.; Horriche, J.; Belgaied, S. Characteriszation of plastic packaging additives: Food contact, stability and toxicity. Arabian J. Chem. 2017, 10, S1938-S1954. [CrossRef]

73. Barnes, D.K.A. Invasions by marine life on plastic debris. Nature 2002, 416, 808-809. [CrossRef]

74. Zettler, E.R.; Mincer, T.J.; Amaral-Zettler, L.A. Life in the "Plastisphere": Microbial Communities on Plastic Marine Debris. Environ. Sci. Technol. 2013, 47, 7137-7146. [CrossRef] [PubMed]

75. Goldstein, M.C.; Carson, H.S.; Eriksen, M. Relationship of diversity and habitat area in North Pacific plastic-associated rafting communities. Mar. Biol. 2014, 161, 1441-1453. [CrossRef]

76. Food and Consumer Product Safety Authority. Migration of Bisphenol A and Plasticizers from Plastic Feeding Utensils for Babies; Report No ND05o410; Food and Consumer Product Safety Authority: Utrecht, The Netherland, 2005; p. 11.

77. Food and Consumer Product Safety Authority. Screening of Plastic Toys for Chemical Composition And hazards. Market Surveillance in the Netherlands; Report ND05o610/01; Food and Consumer Product Safety Authority: Utrecht, The Netherlans, 2005; p. 17.

78. Bradley, E.; Coulier, L. An Investigation into the Reaction and Breakdown Products from Starting Substances Used to Produce Food Contact Plastics; Report FD 07/01; CSL Sand Hutton: York, UK, 2007; p. 628.

79. Hansen, E.; Nilsson, N.; Vium, K.S.R. Hazardous Substances in Plastics. Survey of Chemical Substances in Consumer Products No. 132; The Danish Environmental Protection Agency: Copenhagen, Denmark, 2014; ISBN 978-87-93283-31-2. 
80. Fierens, T.; Servaes, K.; Van Holderbeke, M.; Geerts, L.; De Henauw, S.; Sioen, I.; Vanermen, G. Analysis of phthalates in food products and packaging materials sold on the Belgian market. Food Chem. Toxicol. 2012, 50, 2575-2583. [CrossRef] [PubMed]

81. Fossi, M.C.; Panti, C.; Guerranti, C.; Coppola, D.; Giannetti, M.; Marsili, L.; Minutoli, R. Are baleen whales exposed to the threat of microplastics? A case study of the Mediterranean fin whale (Balaenoptera physalus). Mar. Pollut. Bull. 2012, 64, 2374-2379. [CrossRef]

82. Fossi, M.C.; Marsili, L.; Baini, M.; Giannetti, M.; Coppola, D.; Guerranti, C.; Caliani, I.; Minutoli, R.; Lauriano, G.; Finoia, M.G.; et al. Fin whales and microplastics: The Mediterranean Sea and the Sea of Cortez scenarios. Environ. Pollut. 2016, 209, 68-78. [CrossRef]

83. Jobling, S.; Reynolds, T.; White, R.; Parker, M.G.; Sumpter, J.P. A variety of environmentally persistent chemicals, including some phthalate plasticiszers, are weakly estrogenic. Environ. Health Perspect. 1995, 103, 582-587. [CrossRef]

84. Duty, S.M.; Silva, M.J.; Barr, D.B.; Brock, J.W.; Ryan, L.; Chen, Z.; Herrick, R.F.; Christiani, D.C.; Hauser, R. Phthalate Exposure and Human Semen Parameters. Epidemiology 2003, 14, 269-277. [CrossRef] [PubMed]

85. Hauser, R.; Calafat, A. Phthalates and human health. Occup. Environ. Med. 2005, 62, 806-818. [CrossRef]

86. Oehlmann, J.; Schulte-Oehlmann, U.; Kloas, W.; Jagnytsch, O.; Lutz, I.; Kusk, K.O.; Wollenberger, L.; Santos, E.M.; Paull, G.C.; Van Look, K.J.W.; et al. A critical analysis of the biological impacts of plasticiszers on wildlife. Philos. Trans. R. Soc. B Biol. Sci. 2009, 364, 2047-2062. [CrossRef]

87. Peijnenburg, W.J.; Struijs, J. Occurrence of phthalate esters in the environment of the Netherlands. Ecotoxicol. Environ. Saf. 2006, 63, 204-215. [CrossRef]

88. Sánchez-Avila, J.; Bonet, J.; Velasco, G.; Lacorte, S. Determination and occurrence of phthalates, alkylphenols, bisphenol A, PBDEs, PCBs and PAHs in an industrial sewage grid discharging to a Municipal Wastewater Treatment Plant. Sci. Total. Environ. 2009, 407, 4157-4167. [CrossRef]

89. Bergé, A. Identification of Sources of Alkylphenols and Phthalates in Urban Area. Comparison of Domestic Discharges to Pure Industrial Wastewater. Master's Thesis, University Paris-Est, Créteil, France, 2012.

90. Bergé, A.; Cladière, M.; Gasperi, J.; Coursimault, A.; Tassin, B.; Moilleron, R. Meta-analysis of environmental contamination by phthalates. Environ. Sci. Pollut. Res. 2013, 20, 8057-8076. [CrossRef]

91. Stanley, M.K.; Robillard, K.A.; Staples, C.A. Phthalate esters (The Handbook of Environmental Chemistry); Staples, C.A., Ed.; Springer: Berlin, Germany, 2003; Volume 3, p. 1.

92. Llompart, M.; Garcia-Jares, C.; Landin, P. Phthalates Esters. In Chromatographic Analysis of the Environment; Nollet, L.M.L., Ed.; CRC Press: Boca Raton, FL, USA, 2006; p. 1103.

93. Bergé, A.; Gasperi, J.; Rocher, V.; Gras, L.; Coursimault, A.; Moilleron, R. Phthalates and alkylphenols in industrial and domestic effluents: Case of Paris conurbation (France). Sci. Total. Environ. 2014, 489, 26-35. [CrossRef] [PubMed]

94. Fries, E.; Dekiff, J.H.; Willmeyer, J.; Nuelle, M.T.; Ebert, M.; Remy, D. Identification of polymer types and additives in marine microplastic particles using pyrolysis-GC/MS and scanning electron microscopy. Environ. Sci. Process. Impacts 2013, 15, 1949-1956. [CrossRef]

95. Kühn, S.; Van Oyen, A.; Booth, A.M.; Meijboom, A.; Van Franeker, J.A. Marine microplastic: Preparation of relevant test materials for laboratory assessment of ecosystem impacts. Chemosphere 2018, 213, 103-113. [CrossRef]

96. Cambridge Polymer Group. Rubber Duck Deformulation; Cambridge Polymer Group Inc.: Boston, MA, USA, 2016.

97. Liu, F.-F.; Liu, G.-Z.; Zhu, Z.-L.; Wang, S.-C.; Zhao, F.-F. Interactions between microplastics and phthalate esters as affected by microplastics characteristics and solution chemistry. Chemosphere 2019, 214, 688-694. [CrossRef]

98. Gray, J.L.E.; Ostby, J.; Furr, J.; Price, M.; Veeramachaneni, D.N.R.; Parks, L. Perinatal Exposure to the Phthalates DEHP, BBP, and DINP, but Not DEP, DMP, or DOTP, Alters Sexual Differentiation of the Male Rat. Toxicol. Sci. 2000, 58, 350-365. [CrossRef]

99. Ema, M.; Miyawaki, E. Adverse effects on development of the reproductive system in male offspring of rats given monobutyl phthalate, a metabolite of dibutyl phthalate, during late pregnancy. Reprod. Toxicol. 2001, 15, 189-194. [CrossRef]

100. Fisher, J.S.; MacPherson, S.; Marchetti, N.; Sharpe, R.M. Human 'testicular dysgenesis syndrome': A possible model using in-utero exposure of the rat to dibutyl phthalate. Hum. Reprod. 2003, 18, 1383-1394. [CrossRef] 
101. Jiang, J.; Ma, L.; Yuan, L.; Wang, X.; Zhang, W. Study on developmental abnormalities in hypospadiac male rats induced by maternal exposure to di-n-butylphthalate (DBP). Toxicology 2007, 232, 286-293. [CrossRef]

102. Shrivastava, A. Introduction to Plastics Engineering-3 Plastic Properties and Testing; Elsevier: Amsterdam, The Netherlands, 2018; ISBN 9780323396196.

103. Subramanian, M.N. Plastics Additives and Testing; Scrivener Publishing LLC: Salem, MA, USA; John Wiley \& Sons, Inc.: Hoboken, NJ, USA, 2013; ISBN 978-1-118-11890-0.

104. Bolgar, M.; Hubball, J.; Groeger, J.; Meromeck, S. Plasticizers. In Handbook for the Chemical Analysis of Plastic and Polymer Additives, 1st ed.; AccuStandard: New Haven, CT, USA; CRC Press Taylor \& Francis Group: Boca Raton, FL, USA, 2007; Available online: https://www.taylorfrancis.com/books/9780429140204 (accessed on 6 October 2020).

105. Wang, H.; Wang, C.; Wu, W.; Mo, Z.; Wang, Z. Persistent organic pollutants in water and surface sediments of Taihu Lake, China and risk assessment. Chemosphere 2003, 50, 557-562. [CrossRef]

106. Lu, Z.; De Silva, A.O.; Peart, T.E.; Cook, C.J.; Tetreault, G.R.; Servos, M.R.; Muir, D.C.G. Distribution, partitioning and bioaccumulation of substituted diphenylamine antioxidants and benzotriazole UV stabilisers in an urban creek in Canada. Environ. Sci. Technol. 2016, 50, 9089-9097. [CrossRef]

107. Wick, A.; Jacobs, B.; Kunkel, U.; Heininger, P.; Ternes, T.A. Benzotriazole UV stabiliszers in sediments, suspended particulate matter and fish of German rivers: New insights into occurrence, time trends and persistency. Environ. Pollut. 2016, 212, 401-412. [CrossRef]

108. Kwon, J.-H.; Chang, S.; Hong, S.H.; Shim, W.J. Microplastics as a vector of hydrophobic contaminants: Importance of hydrophobic additives: Hydrophobic organic contaminants from microplastics. Integr. Environ. Assess. Manag. 2017, 13, 494-499. [CrossRef]

Publisher's Note: MDPI stays neutral with regard to jurisdictional claims in published maps and institutional affiliations. 